\title{
The Effect of Core Training on Fitness, Trunk Isokinetic Muscular Function, and Body-Composition in Boxing Athletes
}

\author{
Sung-Ho Ahn'1, Jin-Seok Lee², Chang-Gyun Kim* \\ 'Gachon University, Seongnam, Korea \\ ${ }^{2}$ Korea Institute of Sport Science, Seoul, Korea
}

Received: July 21, 2018

Accepted: September 28, 2018

Published online: October 31, 2018

Keywords:

Body composition

Boxing

Core training

Fitness

Isokinetic muscular function
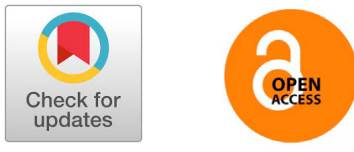

\section{ABSTRACT}

OBJECTIVES The purpose of this study was to investigate the effect of core training on boxer's fitness, trunk insokinetic muscular function, and body-composition.

METHODS Sixteen boxing athletes participated in two trials: (1) core training, and (2) control. Fitness factors, trunk isokinetic muscular function, and body composition measurements were performed at pre $(0$ week), post (8 weeks).

RESULTS Core training was effective in improving trunk flexion, single leg stance, whole body reaction time, grip strength in post-test than in pre-test. Also, was effective in improving $30 \% \mathrm{sec}$ peak torque of flexor, $120 \% \mathrm{sec}$ mean torque of extensor in post-test than in pre-test. Core raining increased body weight and body fat mass.

CONCLUSIONS These suggest that core training can have a positive impact on the performance of boxers.

(c) The Asian Society of Kinesiology and the Korean Academy of Kinesiology
서론

복싱은 체중별로 나뉘어 같은 체급의 두 경기자가 양 손에 글러브를 착용하고 사각의 링 위에서 상대의 상반신 을 치고 받아, 녹아웃이나 판정승을 겨루는 경기이다 [1]. 복싱 경기는 3 분 3 회전 동안 전신을 활용해서 공격과 방 어를 지속적으로 실시하기 때문에 체력적으로 우수한 선 수들이 실전 경기에서도 최상의 경기력을 발휘할 수 있다 [2]. 또한, 3 라운드 동안 부상을 최소화 하며 경기에서 지속

*Correspondence: Chang-Gyun Kim, Department of Physical Education, Gachon University, 1342 Seongnam-daero Sujeong-gu, Gyeonggi-do, Republic of Korea E-mail:ckkim@gachon.ac.kr
적으로 강한 공격력을 발휘 할 수 있는 능력이 필요하기에 체력이 무엇보다도 중요하다 [3]. 복싱의 기본 자세는 앞 으로 약간 허리를 굽힌 자세로, 무게 중심이 전방으로 기 울어진 스탠스를 계속적으로 취하게 된다 [4]. 이러한 복 싱 종목의 특이적 자세의 반복은 척주 만곡 각도에 부정적 인 영향을 미쳐 체위의 비대칭과 체형의 변형을 초래할 수 있으며, 이는 관절가동범위의 저하와 함께 요부 신전 근력 감소에 원인이 될 수 있다 [5]. 관절가동범위 제한과 유연 성 감소 현상은 엘리트 운동 선수들의 체력 수준을 평가하 는 바로미터일 뿐만 아니라 스포츠 상해와도 밀접한 관련 이 있다 [6]. 이와 관련하여 복싱 선수에게는 신체 중심부 의 근력 향상과 유연성 강화를 목적으로 코어 근육을 강화 하는 트레이닝이 효과적일 수 있는데 신체 균형을 유지하 
Table 1. Physical characteristic of subjects

\begin{tabular}{lcccccc}
\hline \multicolumn{1}{c}{ Group } & Height $(\mathrm{cm})$ & Weight $(\mathrm{kg})$ & Age $(\mathrm{yrs})$. & $\mathrm{BMl}\left(\mathrm{kg} / \mathrm{m}^{2}\right)$ & $\mathrm{SBP}(\mathrm{mmHg})$ & $\mathrm{DBP}(\mathrm{mmHg})$ \\
\hline \multicolumn{1}{|c}{ Training $(\mathrm{n}=8)$} & $175.38 \pm 5.04$ & $72.515 \pm 13.29$ & $27.37 \pm 2.35$ & 14.93 & $122.87 \pm 2.03$ & $81.75 \pm 1.66$ \\
Control $(\mathrm{n}=8)$ & $172.16 \pm 6.21$ & $64.76 \pm 11.14$ & $25.00 \pm 3.58$ & 11.56 & $119.87 \pm 4.05$ & $79.87 \pm 4.38$ \\
\hline $\begin{array}{l}\text { Data were presented as mean } \pm \mathrm{SD} \\
\text { BMl: body mass index }\end{array}$ & & & & & \\
SBP: systolic blood pressure \\
DBP: diastolic blood pressure
\end{tabular}

고 근력을 향상시킬 수 있기 때문이다 [7]. 코어 트레이닝 은 사지의 근육이 기능적 활동을 할 수 있도록 작용하는 척주, 복부, 골반 등의 체간 근육 안정성을 높인다 [8]. 코 어의 체계적인 트레이닝은 체간의 유연성과 근력을 증진 하는 동시에 [7] 척주 만곡 각도를 개선할 수 있다 [9]. 선 행연구에서는 균형 강화와 코어 근 강화의 기능적 수행으 로 구성된 코어 트레이닝이 신체적 기능 향상에 영향을 미친다고 보고하였다 [10]. 뿐만 아니라 요부의 근육은 하 지의 움직임에도 중요한 역할을 한다 [11]. 이와 관련하여 선행연구에서는 복횡근과 다열근 근력을 강화한 코어 안 정화 운동에 의해 하지 민첩성과 순발력, 근지구력 등 기 초체력이 유의하게 증가하였음을 관찰한 바 있다 $[12,13$, 14]. 요부와 대퇴 근력 발휘는 상관성이 높고 요부 근력의 강화는 대퇴의 원활한 근력 발휘에 긍정적인 영향을 미칠 수 있다 [15]. 이처럼 운동능력수행 향상과 함께 상해 예방 을 위한 측면에서 요부의 근력 및 근 밸런스가 매우 중요 하기에 중심부 강화 훈련인 코어 트레이닝의 효과적이라 고 권장하고 있다 [16]. 그러나스포츠 현장에서 복싱 선수 를 대상으로 코어 트레이닝의 효과를 규명한 연구는 부족 한 실정이며, 코어 트레이닝에 따른 신체구성 및 기술 체 력과 요부 등속성 근기능에 미치는 영향에 관한 연구도 부족한 실정이다.

따라서 본 연구는 복싱 선수들을 대상으로 코어 트레 이닝을 8 주 동안 실시하여 체력, 요부 등속성 근기능 및 신체구성에 미치는 영향을 검증함으로써 복싱 선수들의 경기력 향상에 대한 기초자료를 제공하는 데 그 목적이 있다.

\section{연구 방법}

\section{연구대상}

본 연구는 대한복싱연맹에 등록되어 있는 경력 3 년 이 상, 의학적 질환이 없는 일반부 복싱 선수 총 16 명을 연구
대상자로 선정하였다. 복싱 선수들은 운동 그룹 $(\mathrm{n}=8)$, 통 제 그룹 $(n=8)$ 으로 무작위 분류하였다 <Table. $1>$. 실험 전 연구대상자들에 게 실험 절차와 목적에 관하여 설명한 후 서면으로 된 동의서를 받고 실험을 진행하였다.

\section{실험설계 및 절차}

연구대상자 선정 전 신체적 특성 (신장, 체중, 체지방 률, 혈압), 설문 및 문진 (병력 사항, 선수 경력), 동의서 작 성 후 실험을 진행하였다. 사전 검사로서 신체구성, 체력 (순발력, 민첩성, 평형성, 유연성, 배근력, 악력), 요부 등 속성 근기능 검사를 하였고 8 주간 주 3 회 코어 트레이닝 을 진행한 후 사전과 동일하게 사후 검사를 진행하였다.

\section{측정항목 및 방법}

신체구성 신체구성은 생체저항측정법에 의한 체성분 측정기 (Inbody 720, Biospace co., Korea)를 이용하여 측정 하였으며, 사전.사후 체중 $(\mathrm{kg})$, 체지방량 $(\mathrm{kg}), \mathrm{BMI}(\mathrm{kg} /$ $\mathrm{m} 2)$, 체지방률 $(\%)$, 제지방량 $(\mathrm{kg})$ 을 산출하였다.

체력 체력은 기초체력검사시스템 (Takei System, Takei co., Japan), 체전굴측정판 (T.K.K 5403, TAKEI co., JAPAN) 을 이용하여 측정하였다. 세부적으로 순발력, 민첩성, 평 형성, 근력, 유연성 요인에 관하여 측정하였으며, 사전.사 후 총 2 회 측정하였다.

순발력은 서전트점프로 하였는데 그 방법은 측정판 위 에 서서 양 손을 허리에 올려두고 위로 힘차게 뛰어 체공 시간을 토대로 높이를 측정하였다. 총 2 회 시도하며, 가장 높을 기록을 결과 값으로 반영하였다. 민첩성은 전신반 응시간으로 측정하였다. 매트 위에 오르고 무릎을 가볍 게 구부린 후 신호가 나오면 수직방향으로 최대한 빠르 게 뛰도록 하였다. 총 2회 시도하며, 가장 높을 기록을 결 과 값으로 반영하였다. 평형성은 눈감고 외발서기로 측 정하였다. 유연성은 체전굴측정판을 이용하여 측정하였 
다. 방법은 체전굴 발판에 올라가 무릎을 쭉 펴고 상체를 굽혀 양손 끝을 수직방향 아래로 최대한 내려가도록 하 며, 이 때 양손 끝에 의해 이동한 거리를 기록하였다. 총 2 회 측정하여 가장 높은 값을 결과 값으로 반영하였다. 근 력은 배근력과 약력으로 측정하였다. 배근력 측정 방법은 발판에 발을 올려놓고 무릎은 쭉 편 상태에서 양 손으로 바를 위로 끌어 허리를 강하게 펴도록 하여 측정하였다. 또한, 악력 측정 방법은 팔을 곧게 펴고 한 손으로 악력계 를 잡고 가장 세게 쥐도록 하여 측정하였다.

요부 등속성 근기능 요부 등속성 근기능은 Isokinetic dynamometer (Cybex 770 Norm, Lumex Inc., Ronkonkoma, $\mathrm{NY}, \mathrm{USA}$ )를 이용하여 측정하여 요부의 근력과 파워, 근지 구력 요인에 관하여 측정하였다. 측정을 위해 대퇴와 상 체를 고정하였다.

각속도 $30 \% \mathrm{sec}$ 로 설정한 후 5 회, $120 \% \mathrm{sec}$ 로 5 회, $150 \%$ $\mathrm{sec}$ 로 25 회로 측정하였으며, 요부 신근과 굴근의 최대근 력 (peak torque, BW\%), 평균파워 (mean torque, BW\%), 총 일량(total work, J)을 산출하였다. 검사 전 10 분 동안 스트 레칭 후 측정 방법에 익숙하도록 연습을 하였고 연구대상 자가 최대의 힘을 발휘할 수 있도록 구두로 격려하였다.

\section{코어 트레이닝 프로그램}

본 연구에서 수행한 코어 트레이닝 프로그램은 코어 트레이닝을 적용한 선행연구를 토대로, 복싱 지도자 3명 과 심도 있는 의견 조율을 거쳐 구성하였다 $[4,17]$. 실험 전 1 주일 동안 동작에 관하여 적용하도록 하고 8 주간 주 3 회 70 분씩 규칙적으로 운동을 실시하였다. 구체적인 코어 트 레이닝 프로그램은 <Table 2>와 같다.

\section{자료처리}

본 연구의 자료처리는 SPSS 21.0 (ver. Korea) 통계 프로 그램을 이용하였으며, 모든 측정항목은 평균 $(\mathrm{m})$ 과 표준 편차 (SD)를 산출하였다. 통계 처리는 먼저 Run 검증을 통해 표집의 무작위성과 Kolmogorow-Smirnov와 Shapiro-Wilk의 검증을 통해 정규성을 확인하였다. 운동 그룹 과 통제 그룹의 사전.사후 효과를 검증하기 위해 Paired t-test를 하였다. 본 연구의 통계학적 유의수준 $(\alpha)$ 은 .05로 설정하였다.

\section{결과}

\section{코어트레이닝에 따른 체력 요인의 변화}

코어 트레이닝 수행 사전.사후 체력 요인 변화는 < Table 3>에 제시한 바와 같다. 순발력 (서전트점프)은 트레이닝 그룹과 통제 그룹 모두 사전.사후 유의한 차이가 나타나 지 않았다. 전신반응시간은 트레이닝 그룹의 경우, 사전. 사후에 유의한 차이가 나타나지 않았으나 통제 그룹에 서는 사전과 비교하여 사후에 유의하게 감소하였다 ( $\mathrm{t}=-$ 4.232, $\mathrm{p}=.004)$. 체전굴은 트레이닝 그룹의 경우, 사전보다

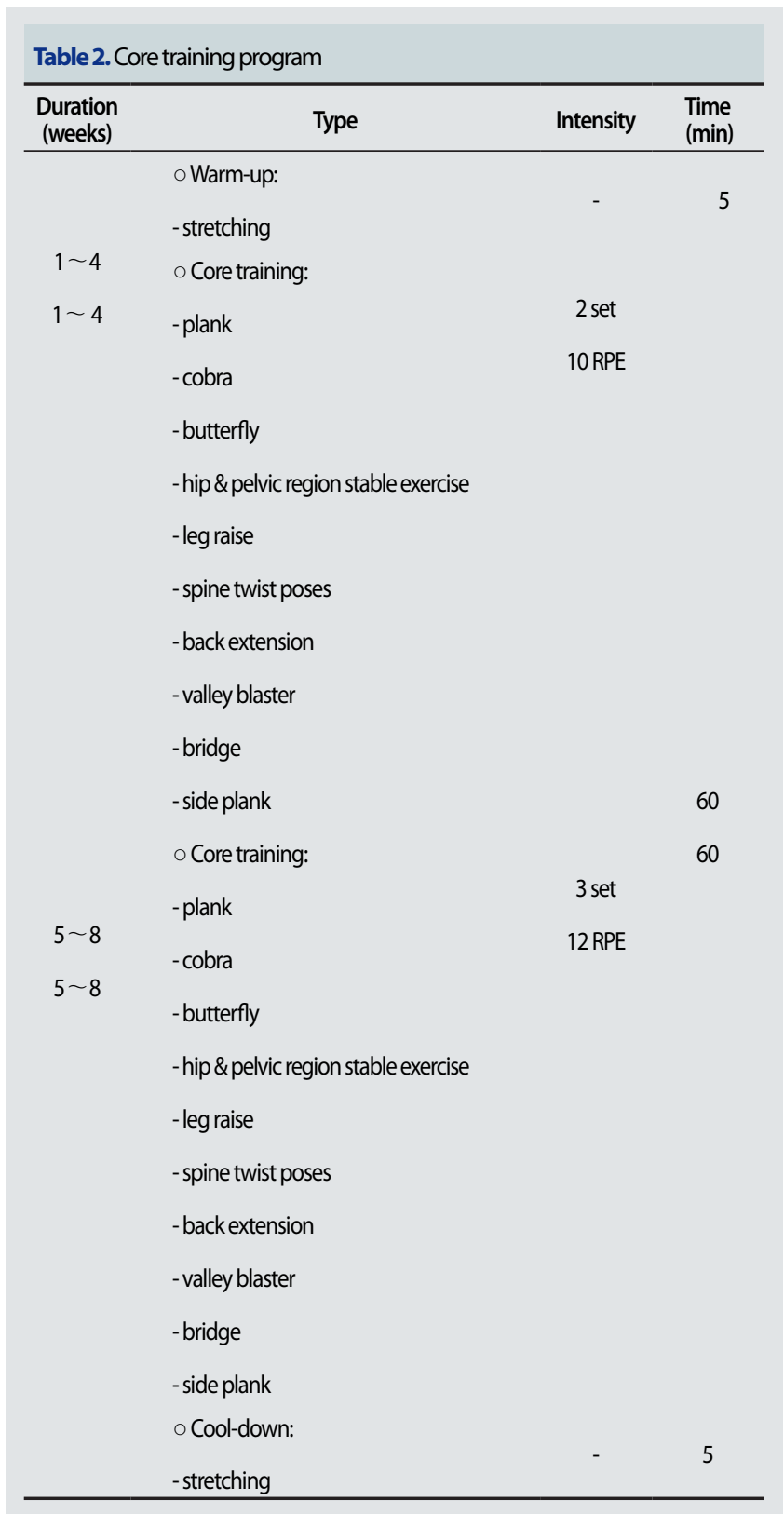


Table 3. Results of physical fitness according to core-training

\begin{tabular}{|c|c|c|c|c|c|c|}
\hline Variables & Grour & & Pre-test & Post-test & $t$ & $p$ \\
\hline \multirow{2}{*}{$\begin{array}{l}\text { Sargent jump } \\
\quad(\mathrm{cm})\end{array}$} & \multicolumn{2}{|c|}{ Training $(n=8)$} & $45.75 \pm 6.31$ & $46.37 \pm 7.53$ & -.372 & .721 \\
\hline & \multicolumn{2}{|c|}{ Control $(n=8)$} & $47.00 \pm 5.58$ & $46.12 \pm 5.81$ & 2.198 & .064 \\
\hline \multirow{2}{*}{$\begin{array}{l}\text { Whole body } \\
\text { reaction time } \\
\text { (sec) }\end{array}$} & \multicolumn{2}{|c|}{ Training $(n=8)$} & $0.289 \pm 0.04$ & $0.280 \pm 0.15$ & .712 & .500 \\
\hline & \multicolumn{2}{|c|}{ Control $(n=8)$} & $0.311 \pm 0.43$ & $0.282 \pm 0.029$ & 4.232 & $.004 *$ \\
\hline \multirow{3}{*}{$\begin{array}{l}\text { Trunkflexion } \\
(\mathrm{cm})\end{array}$} & \multicolumn{2}{|c|}{ Training $(n=8)$} & $12.32 \pm 5.66$ & $16.71 \pm 3.58$ & -4.067 & $.005^{* *}$ \\
\hline & \multicolumn{2}{|c|}{ Control $(n=8)$} & $10.66 \pm 5.29$ & $13.67 \pm 4.60$ & -2.351 & .051 \\
\hline & Training $(n=8)$ & Left & $28.87 \pm 28.25$ & $54.57 \pm 52.31$ & -2.225 & .061 \\
\hline \multirow{3}{*}{$\begin{array}{l}\text { Single leg stance } \\
\quad(\mathrm{sec})\end{array}$} & Control $(n=8)$ & Left & $19.37 \pm 12.56$ & $35.87 \pm 29.84$ & -1.680 & .137 \\
\hline & Training $(\mathrm{n}=8)$ & Right & $21.75 \pm 17.06$ & $37.75 \pm 24.38$ & -2.694 & $.031^{*}$ \\
\hline & Control $(n=8)$ & Right & $21.12 \pm 17.49$ & $39.25 \pm 24.59$ & -1.679 & .137 \\
\hline \multirow{3}{*}{$\begin{array}{l}\text { Back strength } \\
(\mathrm{kg})\end{array}$} & \multicolumn{2}{|c|}{ Training $(n=8)$} & $138.25 \pm 38.42$ & $142.75 \pm 29.45$ & -899 & .398 \\
\hline & \multicolumn{2}{|c|}{ Control $(n=8)$} & $133.00 \pm 34.59$ & $140.87 \pm 34.34$ & -1.035 & .335 \\
\hline & Training $(n=8)$ & Left & $41.95 \pm 9.19$ & $44.17 \pm 9.04$ & -3.252 & $.014^{*}$ \\
\hline \multirow{3}{*}{$\begin{array}{l}\text { Grip strength } \\
(\mathrm{kg})\end{array}$} & Control $(n=8)$ & Left & $39.77 \pm 7.42$ & $38.97 \pm 7.41$ & .520 & .619 \\
\hline & Training $(\mathrm{n}=8)$ & Right & $42.00 \pm 6.56$ & $43.57 \pm 4.11$ & -1.061 & .324 \\
\hline & Control $(n=8)$ & Right & $41.16 \pm 6.30$ & $39.07 \pm 7.57$ & 2.221 & .062 \\
\hline
\end{tabular}

Table 4. Results of trunk isokinetic muscular function according to core-training

\begin{tabular}{|c|c|c|c|c|c|}
\hline Variables & Group & Pre-test & Post-test & $\mathrm{t}$ & $P$ \\
\hline \multirow{2}{*}{$\begin{array}{c}30 \% \mathrm{sec} \\
\text { Extensor PT } \\
(\% \mathrm{BW})\end{array}$} & Training $(n=8)$ & $352.37 \pm 72.51$ & $396.37 \pm 81.48$ & -.2 .244 & .060 \\
\hline & Control $(n=8)$ & $260.62 \pm 58.90$ & $245.87 \pm 68.69$ & 3.175 & .016 \\
\hline \multirow{2}{*}{$\begin{array}{l}30 \% / \mathrm{sec} \\
\text { Flexor PT } \\
\text { (\%BW) }\end{array}$} & Training $(n=8)$ & $273.37 \pm 46.56$ & $303.00 \pm 37.61$ & -2.408 & $.047^{*}$ \\
\hline & Control $(n=8)$ & $442.00 \pm 141.84$ & $311.75 \pm 57.53$ & 1.855 & .106 \\
\hline \multirow{2}{*}{$\begin{array}{c}120^{\circ} / \mathrm{sec} \\
\text { Extensor MT } \\
(\% \mathrm{BW})\end{array}$} & Training $(n=8)$ & $261.00 \pm 89.84$ & $314.13 \pm 61.79$ & -2.070 & 0.77 \\
\hline & Control $(n=8)$ & $401.57 \pm 150.55$ & $312.14 \pm 58.98$ & 2.095 & .081 \\
\hline \multirow{2}{*}{$\begin{array}{c}120^{\circ} / \mathrm{sec} \\
\text { Flexor MT } \\
\text { (\%BW) }\end{array}$} & Training $(n=8)$ & $294.50 \pm 109.71$ & $332.50 \pm 64.81$ & -1.075 & .318 \\
\hline & Control $(n=8)$ & $292.00 \pm 75.58$ & $305.45 \pm 110.32$ & -.403 & .701 \\
\hline \multirow{2}{*}{$\begin{array}{c}150^{\circ} / \mathrm{sec} \\
\text { Extensor J } \\
(\% \mathrm{BW})\end{array}$} & Training $(n=8)$ & $5327.75 \pm 1493.21$ & $5362.87 \pm 1506.60$ & -.059 & .954 \\
\hline & Control $(n=8)$ & $5429.12 \pm 1523.83$ & $5993.87 \pm 1992.56$ & -1.055 & .327 \\
\hline \multirow{2}{*}{$\begin{array}{l}150 \% \text { sec } \\
\text { Flexor J } \\
\text { (\%BW) }\end{array}$} & Training $(n=8)$ & $5660.25 \pm 2775.82$ & $5087.87 \pm 1543.47$ & .723 & .493 \\
\hline & Control $(\mathrm{n}=8)$ & $7145.00 \pm 2995.53$ & $5666.50 \pm 1027.53$ & 1.888 & .101 \\
\hline
\end{tabular}

사후에 유의하게 증가하였으며 $(\mathrm{t}=-4.067, \mathrm{p}=.005)$, 통제 그 타냈다 ( $\mathrm{t}=-2.351, \mathrm{p}=.051)$. 평형성 (외발서기)는 좌측의 경 룹에서는 사전보다사후에 유의하게 증가하는 경향을 나 우 트레이닝 그룹과 통제 그룹 모두 사전·사후에 유의한 


\begin{tabular}{|c|c|c|c|c|c|}
\hline Variables & Group & Pre-test & Post-test & $t$ & $p$ \\
\hline \multirow{2}{*}{$\begin{array}{l}\text { Weight } \\
(\mathrm{kg})\end{array}$} & Training $(n=8)$ & $72.51 \pm 13.29$ & $74.53 \pm 13.97$ & -3.481 & $.010^{* *}$ \\
\hline & Control $(n=8)$ & $64.76 \pm 11.14$ & $64.51 \pm 12.13$ & .569 & .587 \\
\hline \multirow{2}{*}{$\begin{array}{l}\text { Fat mass } \\
(\mathrm{kg})\end{array}$} & Training $(n=8)$ & $11.32 \pm 6.67$ & $12.35 \pm 7.35$ & -2.832 & $.025^{* *}$ \\
\hline & Control $(n=8)$ & $7.61 \pm 2.65$ & $7.76 \pm 2.92$ & -.602 & .566 \\
\hline \multirow{2}{*}{$\begin{array}{l}\text { \%Fat } \\
(\%)\end{array}$} & Training $(n=8)$ & $14.93 \pm 6.23$ & $15.87 \pm 6.39$ & -2.323 & .053 \\
\hline & Control $(n=8)$ & $11.56 \pm 2.43$ & $11.72 \pm 2.26$ & -.419 & .688 \\
\hline \multirow{2}{*}{$\begin{array}{l}\text { Lean mass } \\
(\mathrm{kg})\end{array}$} & Training $(n=8)$ & $61.18 \pm 8.63$ & $61.46 \pm 10.03$ & -.287 & .783 \\
\hline & Control $(n=8)$ & $57.15 \pm 8.91$ & $57.00 \pm 9.29$ & .514 & .623 \\
\hline
\end{tabular}

차이가 나타나지 않았다. 반면, 우측 다리의 경우, 트레 이닝 그룹에서 사전보다 사후에 유의하게 증가하였으나 $(\mathrm{t}=-2.694, \mathrm{p}=.031)$ 통제 그룹에서는 유의한 차이가 나타나 지 않았다. 근력 요인 중 배근력은 트레이닝 그룹과 통제 그룹 모두 사전·사후에 유의한 차이가 나타나지 않았다. 근력 요인 중 악력은 좌측의 경우, 트레이닝 그룹에서 사 전보다 사후에 유의하게 증가하였으나 $(\mathrm{t}=-3.252, \mathrm{p}=.014)$ 통제 그룹에서는 통계적으로 유의한 차이가 나타나지 않 았다. 우측 악력은 트레이닝 그룹과 통제 그룹 모두 사전. 사후에 유의한 차이가 나타나지 않았다.

\section{코어트레이닝에 따른 요부 등속성 근기능의 변화}

코어 트레이닝 수행 전.후 요부 등속성 근기능의 변화 는 < Table $4>$ 에 제시한 바와 같다. $30 \% \mathrm{sec}$ 신근 피크토크 는 트레이닝 그룹과 통제 그룹 모두 사전.사후에 유의한 차이가 나타나지 않았다. $30 \% \mathrm{sec}$ 굴근 피크토크는 트레이 닝 그룹의 경우, 사전보다 사후에 유의하게 증가하였으 나 $(\mathrm{t}=-2.408, \mathrm{p}=.047)$ 통제 그룹에서는 유의한 차이가 나타 나지 않았다. $120 \% \mathrm{sec}$ 신근 평균토크는 트레이닝 그룹의 경우, 사전보다 사후에 증가하는 경향을 나타냈으나 $(\mathrm{t}=-$ $2.070, \mathrm{p}=.077$ ) 통제 그룹의 경우, 사전보다 사후에 유의하 게 감소하는 경향을 나타냈다 $(\mathrm{t}=-2.095, \mathrm{p}=.081) .120 \% \mathrm{sec}$ 굴근 평균토크는 트레이닝 그룹과 통제 그룹 모두 사전. 사후에 유의한 차이가 나타나지 않았다. $150 \% \mathrm{sec}$ 신근 총 일량은 트레이닝 그룹과 통제 그룹 모두 사전.사후에 유 의한 차이가 나타나지 않았으며, $150 \%$ sec 굴근 총일량도 트레이닝 그룹과 통제 그룹 모두 사전.사후에 유의한 차 이가 나타나지 않았다.

\section{코어트레이닝에 따른 신체구성의 변화}

코어 트레이닝 수행 사전·사후 신체구성의 변화는 <Table 5>에 제시한 바와 같다. 체중은 트레이닝 그룹의 경우, 사전보다 사후에 유의하게 증가하였으며 ( $\mathrm{t}=-3.481$, $\mathrm{p}=.010$ ), 통제 그룹에서는 유의한 차이가 나타나지 않았 다. 체지방량은 트레이닝 그룹의 경우, 사전보다 사후에 유의하게 증가하였으며 $(\mathrm{t}=-2.832, \mathrm{p}=.025)$, 통제 그룹에서 는 유의한 차이가 나타나지 않았다. 체지방률은 트레이 닝 그룹의 경우, 사전보다 사후에 증가하는 경향을 나타 냈으나 $(\mathrm{t}=-2323, \mathrm{p}=.053)$ 통제 그룹의 경우, 유의한 차이가 나타나지 않았다. 제지방량은 트레이닝 그룹과 통제 그룹 모두 사전.사후에 유의한 차이가 나타나지 않았다.

\section{논의}

본 연구에서는 코어트레이닝에 따른 체력 요인의 변화 를 살펴본 결과, 코어트레이닝이 유연성과 평형성, 그리 고 악력을 향상시켰음을 입증하였다. 복싱은 앞으로 약 간 허리를 굽힌 자세 즉 무게 중심이 전방으로 기울어진 스탠스를 계속적으로 취하는 특성으로 체위의 비대칭과 체형의 변형을 초래할 수 있다. 이와같이, 복싱의 특성상, 불균형한 자세의 지속은 요부 근력 감소와 통증을 호소할 수 있으며, 관절의 가동범위를 축소할 수 있기에 $[5,18,19]$ 인체의 중심부 즉 코어의 유연성 및 근력을 강화하는 것 이 무엇보다도 중요하다고 할 수 있겠다. 척주 및 골반, 그 리고 인체의 효율적인 힘 발휘를 위해 코어 근육의 안정 성은 필수적이다 [20]. 선행연구들에서는 코어트레이닝 을 적용한 후 유연성이 증가하였다고 보고하였는데 [2123] 이는 본 연구의 결과와 일치한 결과이다. 유연성 향 
상과 관련하여 선행연구에서는 상해 예방과 함께 골프 선 수의 클럽헤드 스피드와 비거리 증가와 같은 경기력 향상 에 이점을 제공할 것이라고 한 바 있다 [24]. 그 뿐만 아니 라 다른 선행연구에서는 코어 트레이닝에 의해 대학 골프 선수의 요부 및 슬관절 최대근력과 비거리를 증가하였음 을 보고하였다 [17]. 아울러, 본 연구에서는 코어트레이닝 에 따른 요부 등속성 근기능 변화에 관하여 살펴본 결과, $30 \% \mathrm{sec}$ 굴근 피크토크는 트레이닝 그룹의 경우, 사전보다 사후에 유의하게 증가하였으며, $120 \% \mathrm{sec}$ 신근 평균토크는 트레이닝 그룹의 경우, 사전보다 사후에 증가하는 경향을 나타냈으나 $(\mathrm{t}=-2.070, \mathrm{p}=.077)$ 통제 그룹의 경우, 사전보다 사후에 감소하는 경향을 나타냄을 관찰하였다 $(\mathrm{t}=-2.095$, $\mathrm{p}=.081$ ). 이는 운동 선수들을 대상으로 코어 트레이닝이 요 부의 등속성 근기능 향상에 효과적이라고 보고한 선행연 구들과 유사한 결과이다 [17]. 요부 안정성과 관련하여 선 행연구에서는 요부의 굴곡력과 신근력 협응 수축력의 증 가로 척추안정성이 증가하고 복부 힘의 증가로 복강 내압 이 높아져 안정성이 증가한다고 보고 하였다 [25]. 그리고 선행연구에서는 신체 중심에서의 큰 자극이 궁극적으로 원위부의 움직임에 영향을 미친다고 보고한 바 있다 [26]. 이렇듯, 코어 트레이닝은 복싱 선수의 신체 중심부를 강화 함으로써 근력 발휘와 통증 개선과 함께 궁극적인 움직임 향상에 기여할 수 있을 것으로 생각된다.

한편, 본 연구 결과, 전신반응시간은 통제 그룹의 경우 사전보다 사후에 유의하게 감소하였으나 트레이닝 그룹 의 경우, 유의한 차이가 나타나지 않았다. 이러한 결과는 본 연구에서의 신체구성 결과와 관련하여 해석할 수 있다. 전신반응시간은 자기 체중 부하로 하는 전신적인 동작이 가미된 시간을 측정하는 것이기 때문이다 [27]. 본 연구에 서는 코어트레이닝에 따른 신체구성 변화를 살펴본 결과, 체중과 체지방량은 트레이닝 그룹의 경우, 사전보다사후 에 유의하게 증가하였으며, 체지방량은 트레이닝 그룹의 경우, 사전보다 사후에 유의하게 증가하였다. 제지방량은 트레이닝 그룹과 통제 그룹 모두 사전·사후에 유의한 차이 가 나타나지 않았다. 이러한 결과는 코어 트레이닝이 체중 감량과 체질량지수 감소 등 신체구성 개선에 효과적이라 고 보고한 선행연구와 상반된 결과이며 $[28,29]$, 이러한 결 과를 토대로, 코어트레이닝이 전신반응시간의 변화를 나 타내지 못했을 가능성이 있을 것으로 생각된다. 코어 트레 이닝이 체지방량 감소에 영향을 미치지 못한 이유는 코어 트레이닝 프로그램의 형태의 차이, 연구대상의 차이 등에
기인한다고 할 수 있겠다. 본 연구에서 적용한 코어 트레 이닝 프로그램은 유연성과 근력 향상을 목적으로, 체중부 하를 이용한 다소 정적인 형태의 동작으로 구성되었다. 이 에, 코어 트레이닝에 의해 수치상 근력은 다소 증가한 양 상을 나타내지만 신체구성 감량에 이점을 제공하기에 어 려움이 있었고 전신반응시간에 영향을 미친 것으로 판단 된다. 이러한 결과는 궁극적으로 강도가 다소 낮았거나 운 동 동작들이 동적이지 못한 탓에, 유의한 효과를 미치지 못한 것으로 생각된다. 뿐만 아니라 자극의 역치 수준이 가장 높은 엘리트 복싱 선수라는 점을 고려해 볼 때 보다 강한 운동 강도 또는 동적인 움직임을 고려한 코어 트레이 닝을 적용해야 할 것으로 생각된다.

\section{결론}

본 연구결과를 종합하면 8주간 코어 트레이닝은 복싱 선수의 체력 및 요부 등속성 근기능에 긍정적인 영향을 미 치기에 복싱 선수의 경기력 향상을 위한 트레이닝 방법의 하나로 코어 트레이닝은 효과적일 것이라 생각된다. 본 연 구에서는 실제 엘리트 복싱 선수를 대상으로 코어 트레이 닝의 효과를 검증하였다는 점에서 의미가 있지만 엘리트 현장의 특성상, 많은 연구대상자를 대상으로 하지 못한 제 한 점이 있다. 따라서 추후의 연구에서는 통계적인 검증력 을 고려하여 보다 많은 복싱 선수를 모집하여 코어 트레이 닝의 효과에 관하여 규명할 필요가 있을 것으로 생각된다.

\section{Acknowledgements}

이 논문은 2018년도에 발행된 석사학위논문에서 발췌하 였음.

\section{Conflicts of Interest}

The authors declare no conflict of interest.

\section{References}

1. El-Ashker S, Nasr M. Effect of boxing exercises on physiological and biochemical responses of Egyptian elite boxers. J Phys Educ Sport. 2012; 12(1):111.

2. Park SH, Park DH, Oh IS, Kim KJ. A study of heart rate and 
blood lactate response during sparring in elite boxers. Korean J Sport Sci. 2008; 19(2):154-160.

3. Kim KJ, Song HS, Min SK. Body Composition and specific physical fitness profiles of the Korean national amateur boxers. Department of sport science. 2016; 25(1):33-42.

4. Cho HC, Roh DS. The effects of lumbar stabilization exercise on pain, lumber flexibility and punching power in Boxers with chronic low back pain. Korean J Phys Educ. 2015; 54(3):541-550.

5. Gossman MR, Sahrmann SA, Rose SJ. Review of length-associated changes in muscle: experimental evidence and clinical implications. Phys Ther. 1982; 62(12):17991808.

6. Dubs L, Gschwend N. General joint laxity. Orthop Trauma Surg. 1988; 107(2): 65-72.

7. Akuthota V, Nadler SF. Core strengthening1. Arch Phys Med Rehabil. 2004; 85:86-92.

8. Joo GN. The effect of 12 weeks core stability exercise on body composition, physical fitness in elementary school taekwondo student. Sports and culture department, major sports industry, Gachon university graduate school of sports culture. 2014; 56(2):1-64.

9. Horak FB, Nashner LM. Central programming of postural movements: adaptation to altered support-surface configurations. J Neurophysiol. 1986; 55(6):13691381.

10. Markovic G, Sarabon N, Greblo Z, Krizanic, V. Effects of feedback-based balance and core resistance training vs. Pilates training on balance and muscle function in older women: A randomized-controlled trial. Arch Gerontol Geriatr. 2015; 61(2):117-123.

11. Jung JH, Kim JT. Comparative analysis on muscle function and EMG of lower extremity in short and long distance athlete. Korean Sport Biomech. 2012; 22(1):916.

12. Granacher U, Schellbach J, Klein K, Prieske O, Baeyens JP, Muehlbauer T. Effects of core strength training using stable versus unstable surfaces on physical fitness in adolescents: a randomized controlled trial. BMC Sports Sci Med Rehabil. 2014; 6(1):40.
13. Mills JD, Taunton JE, Mills WA. The effect of a 10-week training regimen on lumbo-pelvic stability and athletic performance in female athletes: a randomized-controlled trial. Phys Ther Sport. 2005; 6(2):60-66.

14. Yoon SD, Sung DH, Park GD. The effect of active core exercise on fitness and foot pressure in Taekwondo club students. J Phys Ther Sci. 2015; 27(2):509-511.

15. Park GY, Kim SJ. Comparison with isokinetic muscle strength and physical fitness between taekwondo player and poomsae player in elementary School. Korean J Elem Phys Educ. 2008; 14(1):37-44.

16. Lee GW. Therapeutic exercise in low back pain. Ann rehabil med. 1995; 19(2):203-208.

17. Kwon SJ, Yang SW. The effect of core training on isokinetic muscle functions of lumbar and college golfers of knee joints and Performance. J Coaching Dev. 2015; 17(3):101-108.

18. Kuprian W. Physical Therapy for Sports. W. B. Saunders Co. 1982: 262-268.

19. Neumann DA, Soderberg GL, Cook TM. Comparison of maximal isometric hip abductor muscle torques between hip sides. Phys Ther. 1988; 68(4):496-502.

20. Akuthota V, Ferreiro A, Moore T, Fredericson M. Core stability exercise principles. Curr Sports Med Rep. 2008; 7(1):39-44.

21. Huh YS, Lee KY, Shin JS. Effect of core training program on the difference on body composition, Cobb's angle, electromyogram, flexibility and consciousness of high school girls with scoliosis. J Korean Living Environ Syst. 2015; 22(3): 469-476.

22. Phrompaet S, Paungmali A, Pirunsan U, Sitilertpisan P. Effects of pilates training on lumbo-pelvic stability and flexibility. Asian J Sports Med. 2011; 2(1):16.

23. Sekendiz B, Cug M, Korkusuz F. Effects of Swiss-ball core strength training on strength, endurance, flexibility, and balance in sedentary women. J Strength Cond Res. 2010; 24(11):3032-3040.

24. Thompson CJ, Osness WH. Effects of an 8-week multimodal exercise program on strength, flexibility, and golf performance in 55-to 79-year-old men. J Aging Phys Activ. 2004; 12(2):144-156. 
25. Arokoski JP, Valta T, Airaksinen O, Kankaanpää M. Back and abdominal muscle function during stabilization exercises. Arch Phys Med Rehabil. 2001; 82(8):10891098.

26. Carroll TJ, Herbert RD, Munn J, Lee M, Gandevia SC. Contralateral effects of unilateral strength training: evidence and possible mechanisms. J Appl Physiol. 2006; 101(5):1514-1522.

27. Won JY. Athlete's(boxing.fencing.kendo) Whole Body Reaction Time According to the Warming-up Exercises and Main Exercises. Nat Sci. 1995; 6:167-178.

28. Kim HS. Effect of core stability training on Body composition and physical fitness in university students. J Coaching Dev. 2012; 14(4):102-110.

29. Lee KK, Kim HD, Back SH. The change of the underwater dolphin kick performance, body composition and physical fitness after core stability exercise and circuit weight training. J Sport Leisure Stud. 2009; 37(2):1281-1292. 